Article

\title{
Iron Speciation in Different Saharan Dust Advections and Effect of the Procedural Blank on the Results From X-ray Absorption Spectroscopy and Selective Leaching Experiments
}

\author{
Chiara Petroselli ${ }^{1,2, *}$, Beatrice Moroni ${ }^{2}$, Stefano Crocchianti ${ }^{2}$, Roberta Selvaggi ${ }^{2}$, \\ Francesco Soggia ${ }^{3}$, Marco Grotti ${ }^{3}(\mathbb{D})$, Francesco d'Acapito ${ }^{4}(\mathbb{C})$ and David Cappelletti ${ }^{2,5, *}$ (i) \\ 1 Faculty of Engineering and Physical Sciences, University of Southampton, University Road, \\ Southampton SO17 1BJ, UK \\ 2 Dipartimento di Chimica, Biologia e Biotecnologie, Universitá degli Studi di Perugia, via Elce di Sotto 8, \\ 06123 Perugia, Italy; b.moroni@tiscali.it (B.M.); stefano.crocchianti@unipg.it (S.C.); \\ roberta.selvaggi@unipg.it (R.S.) \\ 3 Dipartimento di Chimica e Chimica Industriale, Universitá degli Studi di Genova, via Dodecaneso 31, \\ 16146 Genova, Italy; soggia@chimica.unige.it (F.S.); grotti@unige.it (M.G.) \\ 4 CNR-IOM-OGG c/o ESRF LISA CRG, 71 Avenue des Martyrs, F-38043 Grenoble, France; dacapito@esrf.fr \\ 5 CNR-ISP, Istituto di Scienze Polari, Area della Ricerca di Bologna, via Gobetti 101, 40129 Bologna, Italy \\ * Correspondence: c.petroselli@soton.ac.uk (C.P.); david.cappelletti@unipg.it (D.C.)
}

Received: 16 May 2020; Accepted: 9 July 2020; Published: 10 July 2020

\begin{abstract}
In this work, we applied X-ray Absorption Spectroscopy (XAS) and selective leaching experiments for investigating iron speciation in different dust advections collected on different unwashed quartz fiber filters. XAS analysis evidenced a predominance of $\mathrm{Fe}(\mathrm{III})$ in 6-fold coordination for Saharan dust and a trend towards Fe(II) and 4-fold coordination in the order: Saharan dust, mixed Saharan, and non-Saharan aerosol samples. The role of the sampling substrate was evaluated explicitly, including in the analysis a set of blank filters. We were able to pinpoint the possible contribution to the overall XAS spectrum of the residual Fe on quartz as the concentration decrease towards the blank value. In particular, the filter substrate showed a negligible effect on the structural trend mentioned above. Furthermore, selective leaching experiments evidenced a predominance of the residual fraction on Fe speciation and indicated the lowest Fe concentrations for which the blank contribution is $<20 \%$ are $1 \mu \mathrm{g}$ for the first three steps of the procedure (releasing the acid-labile, reducible and oxidizable phases, respectively) and $10 \mu \mathrm{g}$ for the last step (dissolving the insoluble residuals).
\end{abstract}

Keywords: iron speciation; Saharan dust; filter blank; XANES; EXAFS; selective leaching experiments; Monte Martano (Central Italy)

\section{Introduction}

The Sahara desert is a significant dust source, emitting 50\% of global mineral dust [1]. Mineral dust is rich in iron compounds, and therefore it plays an essential role in the iron cycle worldwide. In fact, mineral dust sources supplies approximately $95 \%$ of the globally averaged iron budget $[2,3]$ and North African deserts are the main emitting areas. Due to their proximity and to the preferred transport routes, Saharan dust is deposited in the Mediterranean basin [4] and in the North Atlantic ocean $[5,6]$. Oceans' iron fertilization promotes phytoplankton activity impacting on the sulfur cycle via increased DMS (dimethyl sulfoxide) production [7] and on the $\mathrm{CO}_{2}$ cycle by enhancing its sequestration from the 
atmosphere [8]. It is worth noting that dust ability to impact on phytoplankton activity is mainly linked to iron solubility and, in turn, to its bioaccessibility (see [9] for definition). Although being the most abundant transition metal in atmospheric aerosols [10], iron solubility in aerosols is highly variable (0.05 to $80 \%$ [11]) and depends not only on the aerosol source but also on atmospheric and cloud processing [12]. In fact, complex atmospheric processing including reductive processes, acid dissolution and photochemistry, can take place during transport. Longo et al. [13] found a correlation between the oxidation state and the estimated travel time, suggesting the extent of atmospheric processing is proportional to the transport time. Photo-reductive processes are mainly active at the aerosol particles' surface [14], however, these processes are reversible and produce a small effect on the overall iron chemical speciation $[10,15]$. Cloud processing, on the contrary, can lead to a significant increase in the soluble $\mathrm{Fe}(\mathrm{II})$ proportion due to the $\mathrm{pH}$ of cloud water [16,17]. The majority of iron in mineral dust is in the Fe(III) oxidation state ([10,18]), in the form of iron oxides like hematite and goethite [19] and accounting for $38 \%$ to $72 \%$ of total elemental iron by mass in Saharan dust [20]. Despite the lower solubility of $\mathrm{Fe}(\mathrm{III})$ compared to $\mathrm{Fe}(\mathrm{II}), \mathrm{Fe}(\mathrm{III})$ is known to contribute largely to the water soluble iron fraction [21]. Additionally to its impact on climate, soluble iron in fine aerosols can take part in reactions generating reactive oxygen species, therefore being identified as a harmful component of aerosol to human health. This characteristic could be relevant to the relationship between high particulate matter concentrations recorded in Europe during severe Saharan dust advections and mortality [22]. Iron speciation can be determined using a variety of techniques, as summarized by Majestic et al. [21], most of them being wet chemical methods that require an extraction step, hence being destructive and time-consuming. Amongst the non-destructive methods, Mössbauer spectroscopy is widely used; however, it requires high amounts of sample to be analysed [23]. X-ray absorption spectroscopy (XAS) allows for direct determination of metals speciation on smaller samples like aerosol filters. Formenti et al. [20] applied XAS to western Sahara mineral dust, Longo et al. [13] applied a combined XANES and wet chemical techniques approach for studying the effect of atmospheric processing on iron speciation after long-range transport and Petroselli et al. [24] compared iron speciation in Saharan dust and steel production emissions. Recently, McDaniel et al. [25] applied XANES for quantifying $\mathrm{Fe}(\mathrm{II})$ in aerosol sampled shipboard in the Atlantic Ocean and investigated the differences between Saharan dust and other provenance samples. XAS is non-destructive and the sampling filter substrate can be analysed directly without any sample preparation step. However, filter substrates can contain high levels of impurities that can affect the sample measurement. Iron, in particular, is present in filter substrates in non-negligible concentrations. Previous literature studies reported XAS data on Nuclepore [26] Teflon $([13,21,27]$ and cellulose ester filters [25]. Moreover, acid-cleaning procedures are usually implemented on filters to be used for XAS analysis in order to minimize the impact of the substrate's trace metals contamination on the analysis [21]. However, filter acid cleaning procedures are expensive and time-consuming and cannot be routinely applied to all the filters used for automated aerosol sampling in air quality monitoring sites. In order to investigate iron speciation in episodic events such as Saharan dust advections on routinely collected aerosol samples, the filter impurities contribution to the XAS spectrum needs to be assessed. The aim of this work is to perform XAS analyses and selective leaching experiments on samples collected during different long-range dust advections on different unwashed quartz fiber filter substrates. To this aim, iron speciation in two severe Saharan dust advections, two mixed Saharan dust advections and two non-Saharan samples will be compared. The filter contamination will be quantitatively evaluated and the effect of the blank filter on the XAS spectrum will also be investigated.

\section{Results}

\subsection{Aerosol Samples Characterization}

In this work, samples from a severe Saharan dust outbreak (SH_Dec), two mixed-Saharan advections (mixSH_Feb and mixSH_Apr) and two different, non-Saharan, air masses (nonSH_Oct and 
nonSH_Jan) are considered. Aerosol mass $\left(\mathrm{PM}_{10}\right.$ and $\left.\mathrm{PM}_{2.5}\right)$ values are reported in Table 1. PM values temporal evolution for the five advections and the corresponding air masses back-trajectories (BTs) are reported in the Supplementary Material, Figures S1 and S2.

Table 1. Samples description: sampling date, filter code, aerosol mass concentration ( $\mathrm{PM}_{10}$ and $\mathrm{PM}_{2.5}$ in $\mu \mathrm{g} \mathrm{m}^{-3}$ ) and iron concentrations determined by ICP-OES for HVS (high volume sampler) $\mathrm{PM}_{10}$ and SWAM PM $\mathrm{PM}_{2.5}$ samples expressed in $\mu \mathrm{g} \mathrm{m}^{-3}$ and converted to atoms $\mathrm{cm}^{-2}$. Errors on the last digit are indicated in parentheses.

\begin{tabular}{|c|c|c|c|c|c|c|}
\hline Date & Code & $\mathrm{PM}_{10}$ & $\mathbf{P M}_{2.5}$ & $\mathrm{PM}_{2.5} / \mathrm{PM}_{10}$ & $\mathrm{Fe}\left[\mu \mathrm{g} \mathrm{m}^{-3}\right]$ & $\mathrm{Fe}\left[\right.$ atoms $\left.\mathrm{cm}^{-2}\right]$ \\
\hline \multirow[t]{2}{*}{30 November 2014} & SH_Dec_PM 10 & 83.9 & & 0.38 & $2.36(1)$ & $7.64(2) \times 10^{16}$ \\
\hline & SH_Dec_PM 2.5 & & 32.3 & 0.38 & $0.39(2)$ & $3.2(1) \times 10^{16}$ \\
\hline \multirow[t]{2}{*}{01 December 2014} & SH_Dec_PM 10 & 86.9 & & 0.36 & $7.81(1)$ & $2.564(3) \times 10^{17}$ \\
\hline & SH_Dec_PM 2.5 & & 31.2 & 0.36 & $0.39(1)$ & $3.30(5) \times 10^{16}$ \\
\hline 19 February 2014 & mix-SH_Feb_PM 10 & 18.9 & 7.7 & 0.41 & $1.174(1)$ & $2.701(3) \times 10^{16}$ \\
\hline 23 April 2014 & mix-SH_Apr_PM 10 & 12.4 & 8.5 & 0.68 & $0.990(1)$ & $1.622(2) \times 10^{16}$ \\
\hline 31 October 2014 & non-SH_Oct_PM 2.5 & 18.9 & 16.9 & 0.89 & $0.099(3)$ & $8.2(2) \times 10^{15}$ \\
\hline 07 January 2015 & non-SH_Jan_PM 2.5 & 22.0 & 18.5 & 0.84 & $0.071(1)$ & $5.91(4) \times 10^{15}$ \\
\hline blank & blank_SWAM & - & - & - & $0.026(4)$ & $2.2(3) \times 10^{15}$ \\
\hline blank & blank_HVS & - & - & - & $0.055(1)$ & $1.44(3) \times 10^{15}$ \\
\hline
\end{tabular}

The pure Saharan dust outbreak was sampled on 30 November and 1 December 2014. The transport came from Algeria and Tunisia, with a contribution from Libya on 30 November only. Both $\mathrm{PM}_{10}$ and $\mathrm{PM}_{2.5}$ values recorded during the advection were extremely high compared to the annual mean value for the year $2014\left(10 \mu \mathrm{g} \mathrm{m}^{-3}\right.$ and $7 \mu \mathrm{g} \mathrm{m}^{-3}$, respectively). The calculated dust load [28], resulted in $80.0 \mu \mathrm{g} \mathrm{m}^{-3}$ and $83.0 \mu \mathrm{g} \mathrm{m}^{-3}$, accounting for $95 \%$ and $96 \%$ of the total $\mathrm{PM}_{10}$, and $29.7 \mu \mathrm{g} \mathrm{m}^{-3}$ and $28.6 \mu \mathrm{g} \mathrm{m}^{-3}$, accounting for $92 \%$ of the total $\mathrm{PM}_{2.5}$ on both days.

The two mixed-Saharan dust events occurred in late winter and early spring. On 19 February 2014 (mix-SH_Feb), Saharan dust from Libya mixed with a significant contribution from the Mediterranean sea was detected (Figure S2c). $\mathrm{PM}_{10}$ and $\mathrm{PM}_{2.5}$ concentrations were $18.9 \mu \mathrm{g} \mathrm{m}^{-3}$ and $7.7 \mu \mathrm{g} \mathrm{m}^{-3}$, respectively and the dust load was $14.9 \mu \mathrm{g} \mathrm{m}^{-3}$, accounting for $75 \%$ of the total $\mathrm{PM}_{10}$. The dust sampled on 23 April 2014 (mix-SH_Apr) was mostly coming from the Iberian Peninsula with a minor contribution from Northern Africa carried by high altitude air masses (Figure S2d). $\mathrm{PM}_{10}$ and $\mathrm{PM}_{2.5}$ values read $12.4 \mu \mathrm{g} \mathrm{m}^{-3}$ and $8.5 \mu \mathrm{g} \mathrm{m}^{-3}$, respectively, and the dust load resulted in $3.0 \mu \mathrm{g} \mathrm{m}^{-3}$, accounting for $24 \%$ of the total $\mathrm{PM}_{10}$ mass concentration. The different $\mathrm{PM}_{2.5} / \mathrm{PM}_{10}$ ratios, together with the different dust contributions, reflect the different extent of the Saharan dust contribution in the two samples. Since high dust load and low $\mathrm{PM}_{2.5} / \mathrm{PM}_{10}$ ratios are typical of Saharan dust advections, the contribution of Saharan dust to mix-SH_Feb resulted higher than in mix-SH_Apr.

The first non-Saharan advection occurred on 31 October 2014 (non-SH_Oct). The sampled air mass came from Eastern Europe and the Balkans where it passed over a very polluted industrialized area in proximity of ground level (Figure S2e). Anthropogenic sources would explain the high PM air mass concentration $\left(18.9 \mu \mathrm{g} \mathrm{m}^{-3}\right)$ and the extremely high $\mathrm{PM}_{2.5} / \mathrm{PM}_{10}$ ratio (0.9) of the sample.

The second non-Saharan advection occurred on 7 January 2015 (non-SH_Jan) and came from Northern Europe. In this case, the air masses spent most of the time in the high troposphere at a great distance from continental Europe (Figure S2f). The long-range advection combined with a regional contribution by anthropogenic aerosols could justify the high $\mathrm{PM}_{2.5}$ mass concentrations $\left(18.9 \mu \mathrm{g} \mathrm{m}^{-3}\right)$ and the high $\mathrm{PM}_{2.5} / \mathrm{PM}_{10}$ ratio (0.8) of this sample. 


\subsection{Total Iron Concentrations}

Total iron concentrations for all the samples and blank filters, are reported in Table 1. Amongst the HVS (high volume sampler) $\mathrm{PM}_{10}$ samples, the highest Fe concentrations are recorded for the pure Saharan dust outbreak, reading $2.36 \mu \mathrm{g} \mathrm{m}^{-3}$ and $7.81 \mu \mathrm{g} \mathrm{m}^{-3}$ for 30 November and 1 December 2014, respectively. Lower Fe concentrations were recorded for the mixed Saharan advections, i.e., $1.17 \mu \mathrm{g} \mathrm{m}^{-3}$ for mix-SH_Feb and $0.99 \mu \mathrm{g} \mathrm{m}^{-3}$ for mix-SH_Apr. The high iron concentrations recorded during the Saharan dust advections, together with the high $\mathrm{PM}_{10}$ mass concentrations and calculated dust loads, suggest the Saharan dust contribution to Fe concentration to be dominating in these samples series. As regards the $\mathrm{PM}_{2.5}$ samples series, Fe concentrations in Saharan dust samples $\left(0.39 \mu \mathrm{g} \mathrm{m}^{-3}\right)$ are about five times higher than in non-Saharan samples $\left(0.099 \mu \mathrm{g} \mathrm{m}^{-3}\right.$ for non-SH_Oct and $0.071 \mu \mathrm{g} \mathrm{m}^{-3}$ for non-SH_Jan). This evidence suggests that the finer particle size fraction plays a role in transporting iron in the atmosphere alongside the coarser one which is typically associated with mineral dust emissions.

\subsection{Iron Speciation}

\subsubsection{X-ray Absorption Spectroscopy}

Figure 1 shows the XANES spectra for $\mathrm{PM}_{10}$ (Figure 1a) and $\mathrm{PM}_{2.5}$ samples (Figure 1b), respectively.
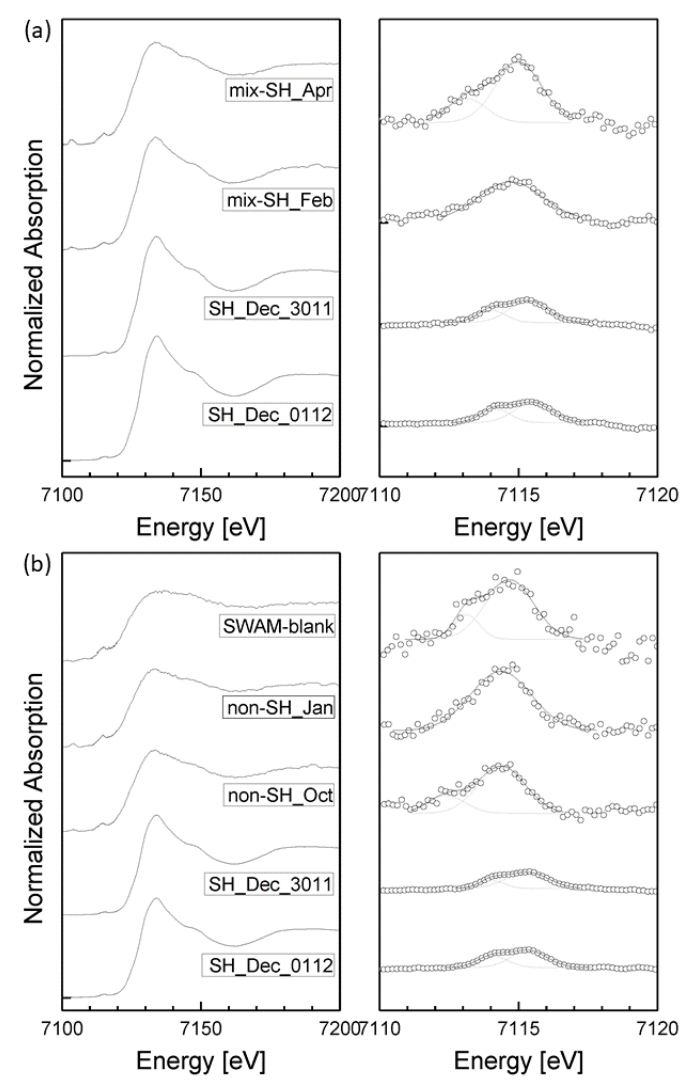

Figure 1. Lefthand panels show the XANES spectra of (a) Saharan dust $\mathrm{PM}_{10}$ samples (SH_Dec_3011 and SH_Dec_0112) and mixed Saharan PM $_{10}$ samples (mix-SH_Feb and mix-SH_Apr); (b) Saharan dust $\mathrm{PM}_{2.5}$ samples (SH_Dec_3011 and SH_Dec_0112), non Saharan PM $_{2.5}$ samples (non-SH_Oct and non-SH_Jan) and SWAM blank filter. A blow-up of the pre-edge features of the same samples is reported in the corresponding righthand panels. Herein the open circles are the experimental points and the lines the model best fits. 
The edge energies for the four samples collected during the SH_Dec advection are nearly coincident at $7125.8 \mathrm{eV}$, compatible with Fe(III). For the mixed-Saharan and the non-Saharan samples, we can observe a gradual shift towards lower energies (from $7124.2 \mathrm{eV}$ to $7122.2 \mathrm{eV}$ ), in an order that reflects the decrease in Saharan dust contribution, aerosol loading and iron concentration (mix-SH_Feb $>$ mix-SH_Apr $>$ non-SH_Oct $>$ non-SH_Jan). Moreover, all the spectra of the Saharan and mixed-Saharan samples result similar, with a peculiar feature around $7149 \mathrm{eV}$, which is not present in the non-Saharan samples. This feature is more pronounced in more ordinate Fe(III) compounds such as hematite, rather than in more disordered compounds like ferrihydrite.

The pre-edge features were fitted in all the samples, and the results are reported in Table 2. The centroid position ranges between $7115.04 \mathrm{eV}$ in Saharan dust samples (HVS PM $\mathrm{P}_{10}$ for SH_Dec-3011) to $7113.93 \mathrm{eV}$ in the non-SH_Jan sample.

Table 2. XANES pre-edge features fit results for $\mathrm{HVS} \mathrm{PM}_{10}$ (upper panel) and $\mathrm{PM}_{2.5}$ (lower panel) samples.

\begin{tabular}{|c|c|c|}
\hline Sample $\left(\mathrm{PM}_{10}\right)$ & $\begin{array}{c}\text { Centroid } \\
( \pm 0.2)\end{array}$ & $\begin{array}{c}\text { Intensity } \\
( \pm 0.02)\end{array}$ \\
\hline SH_Dec-3011 & 7114.9 & 0.05 \\
\hline SH_Dec-0112 & 7115.0 & 0.05 \\
\hline mix-SH_Feb & 7114.7 & 0.11 \\
\hline mix-SH_Apr & 7114.5 & 0.17 \\
\hline Sample $\left(\mathrm{PM}_{2.5}\right)$ & $\begin{array}{c}\text { Centroid } \\
( \pm 0.2)\end{array}$ & $\begin{array}{c}\text { Intensity } \\
( \pm 0.02)\end{array}$ \\
\hline SH_Dec-3011 & 7115.0 & 0.05 \\
\hline SH_Dec-0112 & 7114.9 & 0.05 \\
\hline non-SH_Oct & 7113.9 & 0.16 \\
\hline non-SH_Jan & 7114.4 & 0.20 \\
\hline SWAM-blank & 7114.4 & 0.20 \\
\hline
\end{tabular}

A comparison of the pre-edge parameters with literature reference data ([29], rescaled according to [30]) is shown in Figure 2. A gradual shift is observed, from high-energies/low-intensities for the pure Saharan dust samples $(\mathrm{a}-\mathrm{d})$ towards lower-energies/higher-intensities for non-Saharan samples. Moreover, the coordination geometry shows a decreasing trend from 6-coordinated in pure Saharan dust and mix-SH_Feb samples to lower coordination (5 and 4) for the other mix-SH and non-SH samples suggesting a less symmetrical Fe(III) coordination geometry with decreasing aerosol loading.

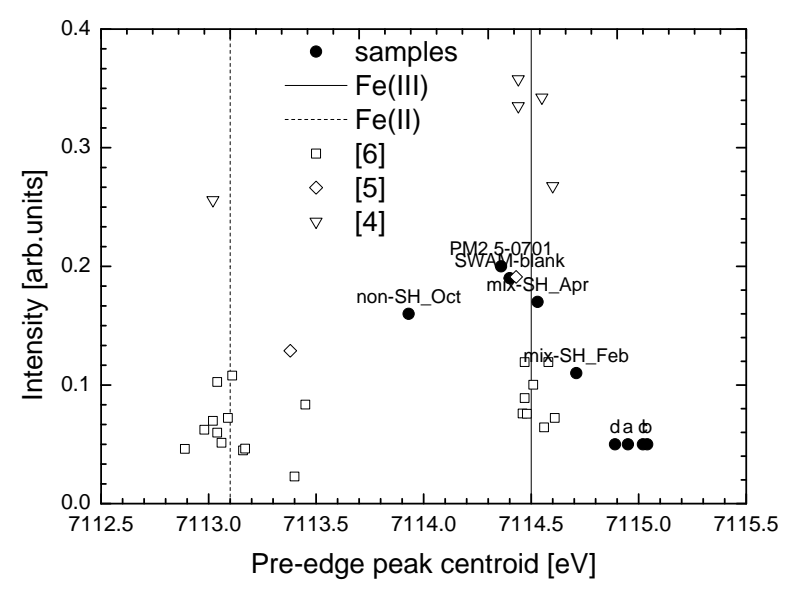

Figure 2. XANES pre-edge features fit parameters scatterplot: comparison between samples and standard Fe(II) and Fe(III) compounds studied in previous literature ([29,30]). Legend for SH_Dec 2014 samples: (a) HVS PM 10 30.11.2014, (b) HVS PM PM $_{10}$ 01.12.2014, (c) SWAM PM 2.5 30.11.2014, (d) SWAM $\mathrm{PM}_{2.5}$ 01.12.2014 
Regarding EXAFS analyses, Figure 3 shows the $\mathrm{k}^{2}$-weighted EXAFS spectra in their relevant fit window and the relative fitted Fourier transforms for HVS $\mathrm{PM}_{10}$ samples (Figure $3 \mathrm{a}$ ), $\mathrm{PM}_{2.5}$ and the SWAM blank filter (Figure 3b).
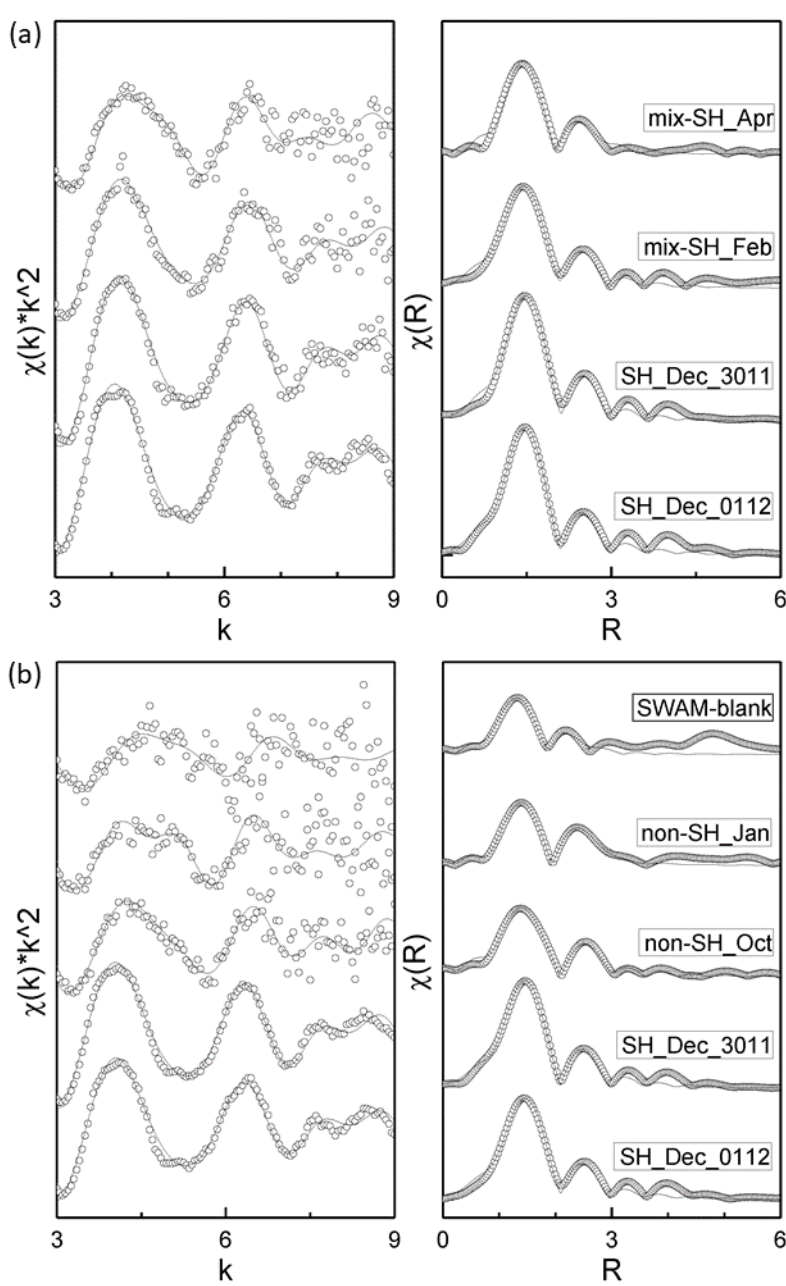

Figure 3. Lefthand panels show EXAFS spectra of (a) Saharan dust PM $_{10}$ samples (SH_Dec_3011 and SH_Dec_0112) and mixed Saharan PM $_{10}$ samples (mix-SH_Feb and mix-SH_Apr); (b) Saharan dust PM $_{2.5}$ samples (SH_Dec_3011 and SH_Dec_0112), non Saharan PM 2.5 samples (non-SH_Oct and non-SH_Jan) and SWAM blank filter. Fourier transformed spectra fits are reported in the corresponding righthand panels. Herein the open circles are the experimental points and the lines the model best fits (see text).

The EXAFS spectrum was reproduced with a two-shell ferrihydrite model, and the fit parameters are shown in Table 3. The coordination number $(\mathrm{N})$ was strongly correlated with the Debye-Waller factors, and was thus obtained by a different first shell fit, linking $\mathrm{N}$ and $\mathrm{r}(\mathrm{Fe}-\mathrm{O})$ using the results of Bond Valence Method calculations ([31,32]).

For the HVS $\mathrm{PM}_{10}$ samples, we observe a decrease in the Fe-O bond distance from $1.98 \AA$ for SH_Dec to 1.95 A for mix-SH_Apr, which agrees with those calculated using the bond valence method (BVM, [32]) for 6 and 5-coordinated Fe(III) (Table S1), and coordination number shows a similar decrease (from 5.5 to 5.2). A similar decreasing trend in both Fe-O bond distances (1.98 $\AA$ to $1.92 \AA$ ) and coordination number (5.5 to 4.9) are observed for $\mathrm{PM}_{2.5}$ samples of $\mathrm{SH} \_D e c$ to non-SH_Jan. Therefore, the overall trend follows the order: SH_Dec $>$ mix-SH_Feb $>$ mix-SH_Apr $>$ non-SH_Oct $>$ non-SH_Jan. It is worth noting that both SWAM PM 2.5 and HVS PM $\mathrm{PM}_{10}$ samples from SH_Dec show the same spectral 
features and fit parameters. We can, therefore, exclude any influence of the sampling system (sampler and substrate) for this event, which is, however, the most intense amongst the presented ones.

Table 3. EXAFS data analysis results. Bond distances (r), coordination numbers $(\mathrm{N})$ and amplitudes $\left(\sigma^{2}\right)$ are obtained from the spectra fits.

\begin{tabular}{|c|c|c|c|c|c|c|}
\hline Sample & $\mathrm{Fe}-\mathrm{O}$ & & & $\mathrm{Fe}-\mathrm{Fe}$ & & \\
\hline & $\mathrm{r}[\AA ̊]$ & $\mathbf{N}$ & $\sigma^{2}\left[\AA^{2}\right]$ & $\mathbf{r}[\AA]$ & $\mathbf{N}$ & $\sigma^{2}\left[\AA^{2}\right]$ \\
\hline \multicolumn{7}{|l|}{$\mathrm{PM}_{10}$} \\
\hline SH_Dec-3011 & $1.98 \pm 0.01$ & $5.4 \pm 0.5$ & $0.009 \pm 0.005$ & $2.96 \pm 0.02$ & $0.8 \pm 0.5$ & $0.02 \pm 0.02$ \\
\hline SH_Dec-0112 & $1.98 \pm 0.01$ & $5.5 \pm 0.4$ & $0.009 \pm 0.003$ & $2.95 \pm 0.01$ & $0.8 \pm 0.3$ & $0.01 \pm 0.01$ \\
\hline mix-SH_Feb & $1.96 \pm 0.01$ & $5.2 \pm 0.4$ & $0.010 \pm 0.004$ & $2.93 \pm 0.01$ & $0.6 \pm 0.3$ & $0.02 \pm 0.02$ \\
\hline mix-SH_Apr & $1.95 \pm 0.01$ & $5.2 \pm 0.2$ & $0.006 \pm 0.005$ & $3.03 \pm 0.01$ & $2.2 \pm 0.9$ & $0.02 \pm 0.02$ \\
\hline \multicolumn{7}{|l|}{$\mathbf{P M}_{2.5}$} \\
\hline SH_Dec-3011 & $1.98 \pm 0.01$ & $5.4 \pm 0.3$ & $0.009 \pm 0.003$ & $2.95 \pm 0.01$ & $0.9 \pm 0.3$ & $0.01 \pm 0.01$ \\
\hline SH_Dec-0112 & $1.98 \pm 0.01$ & $5.5 \pm 0.6$ & $0.010 \pm 0.005$ & $2.95 \pm 0.02$ & $0.8 \pm 0.5$ & $0.02 \pm 0.02$ \\
\hline non-SH_Oct & $1.93 \pm 0.01$ & $4.8 \pm 0.3$ & $0.009 \pm 0.004$ & $2.94 \pm 0.01$ & $0.9 \pm 0.3$ & $0.01 \pm 0.01$ \\
\hline non-SH_Jan & $1.92 \pm 0.01$ & $4.9 \pm 0.1$ & $0.004 \pm 0.002$ & $2.98 \pm 0.01$ & $4.8 \pm 0.6$ & $0.02 \pm 0.01$ \\
\hline SWAM-blank & $1.84 \pm 0.01$ & $4.4 \pm 0.1$ & $0.008 \pm 0.004$ & $2.84 \pm 0.01$ & $1.1 \pm 0.1$ & $0.01 \pm 0.01$ \\
\hline
\end{tabular}

The second shell Fe-Fe distance is about $2.95 \AA$ in the majority of the samples. The slight variations observed between the samples can be ascribed to structural defects and partial substitution of Fe(II) and $\mathrm{Fe}(\mathrm{III})$ on the same site, while the much shorter distance in the blank filter is in line with a different coordination geometry.

In order to get an insight on blank filter contribution to the XAS spectrum, a SWAM quartz fiber filter was analysed. Despite the spectrum of a blank HVS filter is not available, we assume the iron local structure to be similar in both cases because the filter material and manufacturer are the same. The XANES spectrum of the blank filter is shown in Figure $1 \mathrm{~b}$ and shows an edge energy of $7121.5 \mathrm{eV}$, compatible with $\mathrm{Fe}(\mathrm{II})$. The EXAFS fit of the blank filter (Figure 3b, Table 3) shows a Fe-O bond distance of $1.84 \AA$, compatible with 4-coordinated Fe(III) (1.87 ̊, [32], Table S1), and a 4.4 coordination. Considering that XANES data are not quantitative, they are in good agreement with EXAFS data. In fact, in the blank filter iron results low coordinated as expected for being an impurity ion in the quartz matrix.

\subsubsection{Selective Leaching Experiments}

Leaching test results are reported in Table 4. Fe concentrations in non-SH_Oct and non-SH_Jan samples were too low to obtain reliable Fe fractionation data after blank subtraction, and they are hence excluded from further analyses.

Table 4. Leaching test results after blank subtraction.

\begin{tabular}{|c|c|c|c|c|c|c|}
\hline Date & Sample & I (\%) & II (\%) & III (\%) & IV (\%) & tot $\mathrm{Fe}(\mu \mathrm{g})$ \\
\hline 24 April 2014 & mix-SH_Apr_PM 10 & 2 & 5 & 23 & 69 & 2.0 \\
\hline 19 February 2014 & mix-SH_Feb_PM 10 & 10 & 11 & 8 & 70 & 11.1 \\
\hline 30 November 2014 & SH_Dec_PM 10 & 14 & 6 & 8 & 72 & 29.6 \\
\hline 01 December 2014 & SH_Dec_PM 10 & 12 & 7 & 8 & 73 & 100.6 \\
\hline 30 November 2014 & SH_Dec_PM 2.5 & 16 & 7 & 8 & 69 & 9.6 \\
\hline 01 December 2014 & SH_Dec_PM 2.5 & 18 & 8 & 13 & 61 & 11.0 \\
\hline
\end{tabular}

Legend: I step: acid-labile fraction, II step: reducible Fe oxides and hydroxides, III step: oxidizable phase, IV step: insoluble residuals.

Saharan dust HVS $\mathrm{PM}_{10}$ samples collected on 30 November and 1 December 2014 show a consistent fractionation, with the iron oxides fraction (step II) accounting for $7 \%$ of total iron. In the mix-SH_Feb sample, fraction II is enriched to $11 \%$ of total Fe, while the mix-SH_Apr sample shows 
lower percentages in the acid-labile and the reducible fractions (step I and II) and higher values in the oxidizable phase, which accounts for $23 \%$ of total Fe.

Comparing $\mathrm{PM}_{10}$ (i.e., HVS samples) and $\mathrm{PM}_{2.5}$ samples for the $\mathrm{SH} \_D e c$ advection event, the iron fractionation for the two different size fractions is consistent on 30 November 2014, but different in the 1 December case. In fact, the $\mathrm{PM}_{2.5}$ fraction shows slightly higher percentages in step I and III and lower residual (step IV) with respect to the coarse fraction.

The blank contribution in the sequential extraction solutions is evaluated for ten atmospheric aerosol samples (listed in Supplementary Material, Table S2) and reported as a function of the total Fe amount (Figure 4). The influence of the procedural blank on the first three steps of the procedure is quite similar and increases as the total Fe amount decreases. The fourth step is characterized by higher blank values than the previous ones, thus affecting the analytical results more severely. We estimate that the reagents account for about $30 \%$ of the total blank values, whereas the remaining $70 \%$ is due to the filter contribution. Finally, Figure 4 shows that the lowest Fe content for which the blank contribution is $<20 \%$, which can be regarded as a good target, resulted to be $1 \mu \mathrm{g}$ for the steps I-II-III and $10 \mu \mathrm{g}$ for step IV.

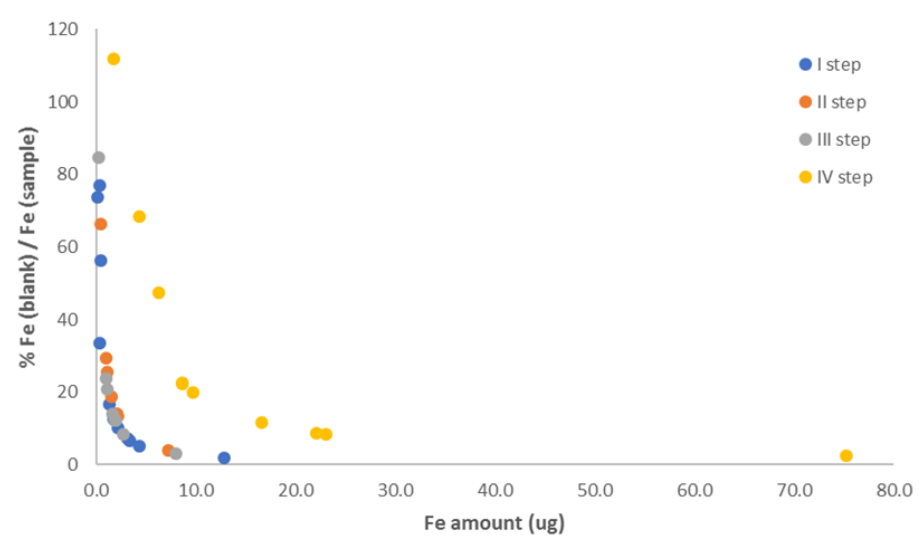

Figure 4. Blank contribution on the results from selective leaching experiments as a function of the Fe amount.

\section{Discussion}

In this work, iron speciation is investigated in different dust advections collected at the Monte Martano site, Central Italy, on different unwashed quartz fiber filters. Five advection events are considered, namely one pure Saharan dust advection, two mixed Saharan advections and two non-Saharan advections. The aerosol mass concentrations and the total iron concentrations decrease from pure Saharan dust to non-Saharan samples reflecting the decrease in Saharan dust contribution to the sampled aerosol. The iron concentrations observed for the Saharan and mix-Saharan dust samples are comparable to the ones recorded by Mc Daniel et al. [25], who reported a range between $1547 \mathrm{ng} \mathrm{m}^{-3}$ and $2491 \mathrm{ng} \mathrm{m}^{-3}$ for Saharan dust collected in the Atlantic Ocean. Mixed Saharan dust advections results are also within the range determined by Longo et al. [13] for long-range transported Saharan dust sampled in Greece and in the Atlantic Ocean (735-1580 $\mathrm{ng} \mathrm{m}^{-3}$ ). These observations confirm Monte Martano is a representative site for studying long-range Saharan dust advections in the Central Mediterranean Basin.

\subsection{Iron Speciation in the Different Advections}

Iron speciation is investigated by both X-ray Absorption Spectroscopy and selective leaching experiments. XANES results evidence Fe(III) is predominant in all the Saharan dust samples, which spectra show common features such as the same edge energy $(7125.8 \mathrm{eV})$, similar spectral shape and pre-edge features parameters. These results are in accordance with the results from McDaniel et al. [25], 
who observed nearly coincident spectra for Saharan dust samples, with an edge energy of $7126 \mathrm{eV}$. Moreover, the shape of the pre-edge features in Saharan dust samples is compatible with the work by Formenti et al. [20], who observed a double peak structure with centroid positioned between $7114 \mathrm{eV}$ and $7116 \mathrm{eV}$ as a signature for iron oxides in Saharan dust. However, the pre-edge energies obtained for Saharan dust are slightly higher than what reported by Longo et al. [13], i.e., pre-edge centroid between $7114.4 \mathrm{eV}$ and $7113.6 \mathrm{eV}$ for dust sampled in Greece, suggesting a less effective atmospheric processing in our samples, that might be attributed to the high velocity of the air masses in the studied Saharan dust advection. Regarding non-Saharan advections, lower edge energies (7124-7122 eV) are compatible with the results of McDaniel et al. [25] for samples with North American and marine provenances. However, unlike Saharan dust which is a well defined and well studied type of aerosol, the few non-Saharan samples presented in this study do not permit a thorough characterization of aerosol transported from different sources to the Monte Martano site.

Both the XANES and the EXAFS regions of the spectrum evidence a shift from mainly Fe(III) in 6-fold coordination towards a mixture of $\mathrm{Fe}(\mathrm{II})$ and $\mathrm{Fe}(\mathrm{III})$, where the latter is still predominant, and lower coordination going from pure Saharan dust to non-Saharan samples in the order: SH_Dec $>$ mix-SH_Feb $>$ mix-SH_Apr $>$ non-SH_Oct $>$ non-SH_Jan. This trend is in accordance with the observations on dust load and total iron concentrations, suggesting it is mainly driven by the decreasing contribution of Saharan dust to the overall dust sampled.

Selective leaching experiments evidence the dominance of the insoluble residual fraction in all the samples, while the iron oxides fraction accounts for about $7 \%$ of total iron on Saharan and mixed-Saharan samples. This percentage is much lower than what reported by Formenti et al. [20], who observed the iron oxides contribution in Saharan dust being in the range 38-72\%, and apparently not in accordance with XAS results, which point towards the presence of Fe(III) oxides in determining the observed spectral features. However, it has to be considered that some iron oxides identified in Saharan dust by XAS speciation analyses (e.g., hematite, goethite, ferrihydrite) could not be completely extracted in step II, hence contributing to the residual insoluble fraction ([33]; [34]; [35]), which accounts for about $70 \%$ for all the Saharan dust samples considered in this study.

The leaching results for the mixed Saharan samples give us an insight on the mixing and ageing of the dust during its permanence in the atmosphere. The mix-SH_Apr sample, in particular, shows higher values in the oxidizable phase (step III) which suggests a higher level of atmospheric processing with respect to the other advections, compatible with the lower velocity of the air mass. This hypothesis is supported by XAS results as well, which show a higher contribution from Fe(II) in the mix-SH_Apr sample with respect to SH_Dec and mix-SH_Feb samples. Finally, the comparison between the two particle size fractions for the SH_Dec event evidence a different fractionation in the $\mathrm{PM}_{2.5}$ sample of 1 December 2014, with respect to the $\mathrm{PM}_{10}$ collected on the same day. This evidence suggests a cleaner Saharan dust advection in the fine fraction compared to the previous day. This observation is supported by previous studies that evidenced a higher degree of contamination by anthropogenic emissions on 30 November compared to 1 December [36].

In summary, iron speciation measurements show a very clear and consistent trend which reflects the contribution of Saharan dust to the overall aerosol composition and give insights on the atmospheric processing of the samples during their long-range transport to Central Italy.

\subsection{Effect of the Procedural Blank on Fe Speciation Measurements}

In order to evaluate the effect of the procedural blank on iron concentrations and speciation, blank HVS and SWAM quartz fiber filters were analysed along with the samples, and their total iron concentrations are reported in Table 1. Comparing the Fe concentrations in blanks and samples, we observed that for the HVS $\mathrm{PM}_{10}$ samples, the blank contribution is always below $6 \%$ of the total iron concentration, due to the high aerosol loading of the filters. For the SWAM samples, on the other hand, the filter contribution results no more negligible and reaches values of 26 and $37 \%$ of the total Fe content in the two non-Saharan samples (non-SH_Oct and non-SH_Jan, respectively). 
The XANES and EXAFS parameters obtained for the blank filters suggest that the contribution of the blank filter becomes gradually more important in determining the XAS spectral features in the XANES region in a trend from the most loaded to the least loaded filter samples (SH_Dec $>$ mix-SH_Feb $>$ mix-SH_Apr $>$ non-SH_Oct $>$ non-SH_Jan). However, the shape of the pre-edge features for the blank filter shows two components, while the shape of the peaks for the non-SH_Jan is mono-modal. Therefore, in the case of XAS analyses, it is not possible to disentangle the effect of the increased blank contribution from the decreased Saharan dust contribution to the observed trend.

Leaching test results show that the blank values are much higher in the last step of the procedure, which dissolves the residual fraction. This can be ascribed both to the use of concentrated acids $\left(\mathrm{HNO}_{3}\right.$, $\mathrm{HCl}$ and $\mathrm{HF}$, see experimental method), which could increase the reagent blank, and to the use of a more aggressive extracting solution, which enhances the Fe released from the filter matrix. Leaching data allowed to quantify the blank contribution to the samples, and it was possible to calculate the minimum Fe concentration for which the blank contribution is lower than $20 \%$, which can be regarded as a good target for unbiased Fe fractionation results.

\section{Materials and Methods}

\subsection{Sampling}

In this study, we considered the most significant dust advections recorded at the rural regional background station of Monte Martano, Central Italy (MM, 1100m a.s.l.; [37]), between February 2014 and January 2015. The site is part of the WMO SDS-WAS (World Meteorological Organization Sand and Dust Storms-Warning Advisory and Assessment System, https://sds-was.aemet.es) network for Saharan dust transport monitoring since 2013 and of the EMEP (European Monitoring and Evaluation Programme, https:/ / www.emep.int) network since 2017. Saharan dust advections are forecasted and identified on the basis of air mass back-trajectories. Back-trajectories (BTs) are calculated using Hysplit v4 [38] using NCEP-GFS (National Centers for Environmental Prediction - Global Forecast System) model data with $1 \times 1^{\circ}$ resolution, and applying four ending altitudes (0, 500, 1000 and $3000 \mathrm{~m}$ a.g.l.) and a 6-hours time resolution [24].

The samples were collected by means of a SWAM dual-channel low volume sampler (FAI instruments, $38.33 \mathrm{~L} \mathrm{~min}^{-1}$ ) equipped with $\mathrm{PM}_{10}$ and $\mathrm{PM}_{2.5}$ impactors and a high volume sampler (Air HVS flow, Analitica Strumenti, $1140 \mathrm{~L} \mathrm{~min}^{-1}$ ) equipped with a $\mathrm{PM}_{10}$ impactor. The filters used on the two samplers are quartz fiber filters, namely Whatman QM $47 \mathrm{~mm}$ and Whatman QMA for SWAM and HVS samplers, respectively. The sampling time for the SWAM sampler is $24 \mathrm{~h}$, while the sampling interval for the high volume sampler was set between 6 and $18 \mathrm{~h}$ according to the duration of the intrusion. Filter samples were kept frozen until analysis, as this preservation method was proven to minimize the loss of $\mathrm{Fe}(\mathrm{II})$ due to oxidating processes [14,39]. Filters were then defrost and cut into pieces of suitable size for the different analyses described in the following paragraphs.

\subsection{Inductively Coupled Plasma Optical Emission Spectroscopy (ICP-OES)}

Samples were acid digested using a Microwave Assisted Reaction System (MARS, CEM Corporation), using $\mathrm{HNO}_{3}$ (Millipore Suprapur, 65\%) and $\mathrm{H}_{2} \mathrm{O}_{2}$ (Carlo Erba Reagents, 30-32\%) in 4:1 (v/v) proportion. Analyses were performed using an Ultima II ICP-OES (Horiba Scientific) equipped with an ultrasonic nebulizer. Iron was quantified choosing the $259.94 \mathrm{~nm}$ wavelength and performing a calibration with five multi-element standard solutions prepared from Précis Quality Control Standard 21 (100 mg $\mathrm{L}^{-1}, 5 \% \mathrm{HNO}_{3}$, Horiba-Jobin Yvon) in a concentration range between 0.01 and $1 \mathrm{ppm}$. The limits of detection (LOD) and of quantification (LOQ) of Fe were estimated from the calibration curve, resulting 0.04 and $0.14 \mathrm{mg} \mathrm{L}^{-1}$, respectively. 


\subsection{Sequential Leaching Extraction}

In order to determine iron fractionation (i.e relative distribution among the various mineralogical phases), the sequential extraction method proposed by Pueyo et al. [40] and adopted by the European Community Bureau of Reference (BCR) was used. The method, originally developed for soil and sediment samples, was also applied to the sequential chemical fractionation of atmospheric aerosols, as reviewed by Smichowski et al. [41]. The BCR procedure consistsof three sequential extraction steps plus a fourth step which allows to quantify Fe concentration in the residual fraction as well. The first step consists of treating the sample with acetic acid for releasing the acid-labile fraction (carbonates and labile organic matter), while in the second step hydroxylamine hydrochloride is used to release the reducible compounds (Mn and Fe oxides and hydroxides). The third step consists of a microwave-assisted digestion with hydrogen peroxide and allows to release the oxidizable phases (organic matter and sulfides). The residues from third step are then acid-digested in the microwave system using a $\mathrm{HNO}_{3}: \mathrm{HCl}: \mathrm{HF} \mathrm{1:3:2} \mathrm{(v/v)} \mathrm{mixture} \mathrm{for} \mathrm{dissolving} \mathrm{the} \mathrm{residual} \mathrm{fraction} \mathrm{(silicates} \mathrm{and}$ alluminosilicates). A more detailed description of the procedure used is reported in Petroselli et al. [35]. All the samples obtained from the various steps were then analysed by inductively coupled plasma atomic emission spectrometry (Vista PRO by Agilent Technologies, Santa Clara, CA, USA), using on-line internal standardization ( $\mathrm{Lu} 291.139 \mathrm{~nm}$ ) and measuring the emission intensity at selected wavelengths: (Fe 234.350, 240.489, $259.837 \mathrm{~nm}$ ).

\subsection{X-ray Absorption Spectroscopy (XAS)}

X-ray Absorption (XAS) spectra at the Fe K-edge $(7112 \mathrm{eV})$ were collected at the European Synchrotron Radiation Facility (ESRF) of Grenoble, France at the LISA (formerly GILDA) CRG beamline (BM08, [42]). The beamline is equipped with a sagittally focusing monochromator using $\operatorname{Si}(311)$ crystals and a pair of Pd-coated mirrors (Ecutoff $=18 \mathrm{keV}$ ) for harmonic rejection and beam focusing. The fluorescence emission from the samples was collected using a 12 elements Ge detector, and at least three scans per sample were averaged in order to improve the signal-to-noise ratio. The XAS spectra were recorded between about 6900 and $7700 \mathrm{eV}$ in order to include both the XANES (X-ray Absorption Near Edge Spectroscopy) and the EXAFS (Extended X-ray Absorption Fine Structure) regions. A metallic Fe foil was placed in the second vacuum chamber and its spectrum was collected in transmission mode during every sample scan in order to provide a reliable energy calibration. The beam size ensures the acquisition of spectra over a macroscopic portion of the sample, and the tests for sample beam damage exclude this eventuality.

The obtained spectra have been then analysed by means of appropriate codes (FEFF8, Athena, Artemis; [43]) to obtain information from both the XANES and the EXAFS regions, separately. The pre-edge features of the XANES part of the spectrum were fitted keeping the number of components at a minimum in all cases in order to determine the centroid position and the intensity of the peaks using Origin(Pro)8 (OriginLab Corporation, Northampton, MA, USA).

Supplementary Materials: The following are available online at http://www.mdpi.com/2073-4433/11/7/735/s1.

Author Contributions: Conceptualization, C.P., B.M. and D.C.; methodology, C.P., M.G., F.d. and D.C.; investigation, C.P., B.M., S.C., R.S., F.S. and M.G.; data curation, C.P. and M.G.; writing-original draft preparation, C.P.; writing-review and editing, C.P., B.M., S.C., R.S., F.S., M.G., F.d. and D.C.; supervision, D.C. and F.d.; project administration, D.C.; funding acquisition, D.C. All authors have read and agreed to the published version of the manuscript.

Funding: This research was funded by the University of Perugia through the FRB2015 grant and by Ministero dell'Istruzione, dell'Università e della Ricerca, AMIS project, through the program "Dipartimenti di Eccellenza-2018-2022".

Acknowledgments: We thank ARPA Umbria for the long standing collaboration in the management of the Monte Martano EMEP station. 
Conflicts of Interest: The authors declare no conflict of interest. The funders had no role in the design of the study; in the collection, analyses, or interpretation of data; in the writing of the manuscript, or in the decision to publish the results.

\section{Abbreviations}

The following abbreviations are used in this manuscript:

$\begin{array}{ll}\text { BCR } & \text { European Community Bureau of Reference } \\ \text { BTs } & \text { Back Trajectories } \\ \text { BVM } & \text { Bond Valence Method } \\ \text { DMS } & \text { Dimethyl Sulfate } \\ \text { EMEP } & \text { European Monitoring and Evaluation Programme } \\ \text { ESRF } & \text { European Synchrotron Radiation Facility } \\ \text { EXAFS } & \text { Extended X-ray Absorption Fine Structure } \\ \text { HNLC } & \text { High Nutrient Low Chlorophyll } \\ \text { HVS } & \text { High Volume Sampler } \\ \text { ICP-OES } & \text { Inductively Coupled Plasma - Optical Emission Spectroscopy } \\ \text { LISA } & \text { Linea Italiana per la Spettroscopia d'Assorbimento x } \\ \text { LOD } & \text { Limit of Detection } \\ \text { LOQ } & \text { Limit of Quantification } \\ \text { MM } & \text { Monte Martano } \\ \text { NCEP-GFS } & \text { National Centers for Environmental Prediction - Global Forecast System } \\ \text { SWAM } & \text { Model of particulate matter sampling instrument (FAI instruments) } \\ \text { WMOSDS-WAS } & \text { World Meteorological Organization Sand and Dust Storms-Warning Advisory and Assessment System } \\ \text { XAS } & \text { X-ray Absorption Spectroscopy } \\ \text { XANES } & \text { X-ray Absorption Near Edge Structure }\end{array}$

\section{References}

1. Prospero, J.; Ginoux, P.; Torres, O.; Nicholson, S.; Gill, T. Environmental characterization of global sources of atmospheric soil dust identified with the Nimbus 7 Total Ozone Mapping Spectrometer (TOMS) absorbing aerosol product. Rev. Geophys. 2002, 40,1-31. [CrossRef]

2. Luo, C.; Mahowald, N.; Bond, T.; Chuang, P.; Artaxo, P.; Siefert, R.; Chen, Y.; Schauer, J. Combustion iron distribution and deposition. Glob. Biogeochem. Cycles 2008, 22. [CrossRef]

3. Mahowald, N.; Engelstaedter, S.; Luo, C.; Sealy, A.; Artaxo, P.; Benitez-Nelson, C.; Bonnet, S.; Chen, Y.; Chuang, P.; Cohen, D.; et al. Atmospheric iron deposition: Global distribution, variability and human perturbations. Annu. Rev. Mar. Sci. 2009, 1, 245-278. [CrossRef] [PubMed]

4. Gkikas, A.; Hatzianastassiou, N.; Mihalopoulos, N.; Katsoulis, V.; Kazadzis, S.; Pey, J.; Querol, X.; Torres, O. The regime of intense desert dust episodes in the Mediterranean based on contemporary satellite observations and ground measurements. Atmos. Chem. Phys. 2013, 13, 12135-12154. [CrossRef]

5. Prospero, J. Saharan dust transport over the North Atlantic Ocean and Mediterranean: An overview. In The Impact of Desert Dust Across the Mediterranean; Guerzoni, S; Chester, R., Eds.; Springer: Dordrecht, The Netherlands, 1996; pp. 133-151.

6. Prospero, J.; Glaccum, R.; Nees, R. Atmospheric transport of soil dust from Africa to South America. Nature 1981, 289, 570-572. [CrossRef]

7. Zhuang, G.; Yi, Z.; Duce, R.; Brown, P. Link between iron and sulphur cycles suggested by detection of Fe(II) in remote marine aerosols. Nature 1992, 355, 537-539. [CrossRef]

8. Smetacek, V.; Klaas, C.; Strass, V.; Assmy, P.; Montresor, M.; Cisewski, B.; Savoye, N.; Webb, A.; d'Ovidio, F.; Arrieta, J.; et al. Deep carbon export from a Southern Ocean iron-fertilized diatom bloom. Nature 2012, 487, 313-319. [CrossRef]

9. Meskhidize, N.; Volker, C.; Al-Abadleh, H.; Barbeau, K.; Bressac, M.; Buck, C.; Bundy, R.; Croot, P.; Feng, Y.; Ito, A.; et al. Perspective on identifying and characterizing the processes controlling iron speciation and residence time at the atmosphere-ocean interface. Mar. Chem. 2019, 217, 103704. [CrossRef] 
10. Fittschen, U.; Meirer, F.; Streli, C.; Wobrauschek, P.; Thiele, J.; Falkenberg, G.; Pepponi, G. Characterization of atmospheric aerosols using Synchrotron radiation total reflection X-ray fluorescence and Fe K-edge total reflection X-ray fluorescence-X-ray absorption near edge structure. Spectrochim. Acta Part B 2008, 63, 1489-1495. [CrossRef]

11. Mahowald, N.; Baker, A.; Bergametti, G.; Brooks, N.; Duce, R.; Jickells, T.; Kybilay, N.; Prospero, J.; Tegen, I. Atmospheric global dust cycle and iron inputs to the ocean. Glob. Biogeochem. Cycles 2005, 19. [CrossRef]

12. Shi, Z.; Krom, M.; Jickells, T.; Bonneville, S.; Carslaw, K.; Mihalopoulos, N.; Baker, A.; Benning, L. Impacts on iron solubility in the mineral dust by processes in the source region and the atmosphere: A review. Aeolian Res. 2012, 5, 21-42. [CrossRef]

13. Longo, A.; Feng, Y.; Lai, B.; Landing, W.; Shelley, R.; Nenes, A.; Mihalopoulos, N.; Violaki, K.; Ingall, E. Influence of atmospheric processes on the solubility and composition of iron in Saharan dust. Environ. Sci. Technol. 2016, 50, 6912-6920. [CrossRef] [PubMed]

14. Takahama, S.; Gilardoni, S.; Russel, L. Single-particle oxidation state and morphology of atmospheric iron. J. Geophys. Res. Atmos. 2008, 113, D22. [CrossRef]

15. Ohta, A.; Tsuno, H.; Kagi, H.; Kanai, Y.; Nomura, M.; Zhang, R.; Terashima, S.; Imai, N. Chemical compositions and XANES speciations of $\mathrm{Fe}, \mathrm{Mn}$ and $\mathrm{Zn}$ from aerosols collected in China and Japan during dust events. Geochem. J. 2006, 40, 363-376. [CrossRef]

16. Jacob, D.; Waldman, J.; Munger, J.; Hoffmann, M. Chemical composition of fogwater collected along the California coast. Environ. Sci. Technol. 1985, 19, 730-736. [CrossRef] [PubMed]

17. Kieber, R.; Skrabal, S.; Smith, B.; Willey, J. Organic complexation of Fe(II) and its impact on the redox cycling of iron in rain. Environ. Sci. Technol. 2005, 39, 1576-1583. [CrossRef]

18. Shi, Z.; Krom, M.; Bonneville, S.; Baker, A.; Bristow, C.; Drake, N.; Mann, G.; Carslaw, K.; McQuaid, J.; Jickells, T.; Benning, L. Influence of chemical weathering and aging of iron oxides on the potential iron solubility of Saharan dust during simulated atmospheric processing. Glob. Biogeochem. Cycles 2011, 25. [CrossRef]

19. Torrent, J.; Schwertmann, U.; Fechter, H.; Alferez, F. Quantitative relationships between soil color and hematite content. Soil Sci. 1983, 136, 354-358. [CrossRef]

20. Formenti, P.; Caquineau, S.; Chevaillier, S.; Klaver, A.; Desboeufs, K.; Rajot, J.; Belin, S.; Briois, V. Dominance of goethite over hematite in iron oxides of mineral dust from Western Africa: Quantitative partitioning by X-ray absorption spectroscopy. J. Geophys. Res. Atmos. 2014, 119, 12740-12754. [CrossRef]

21. Majestic, B.; Schauer, J.; Shafer, M. Application of synchrotron radiation for measurements of iron red-ox speciation in atmospherically processed aerosols. Atmos. Chem. Phys. 2007, 7, 2475-2487. [CrossRef]

22. Stafoggia, M.; Zauli-Sajani, S.; Pey, J.; Samoli, E.; Alessandrini, E.; Basagana, X.; Cernigliaro, A.; Chiusolo, M.; Demaria, M.; Dìaz, J.; et al. Desert dust outbreaks in Southern Europe: Contribution to daily PM $_{10}$ concentrations and short-term associations with mortality and hospital admissions. Environ. Health Perspect. 2015. [CrossRef] [PubMed]

23. Hoffmann, P.; Dedik, A.; Ensling, J.; Weinbruch, S.; Weber, S.; Sinner, T.; Gulich, P.; Ortner, H. Speciation of iron in atmospheric aerosol samples. J. Aerosol Sci. 1996, 27, 325-337. [CrossRef]

24. Petroselli, C.; Crocchianti, S.; Moroni, B.; Castellini, S.; Selvaggi, R.; Nava, S.; Calzolai, G.; Lucarelli, F.; Cappelletti, D. Disentangling the major source areas for an intense aerosol advection in the Central Mediterranean on the basis of Potential Source Contribution Function modeling of chemical and size distribution measurements. Atmos. Res. 2018, 204, 67-77. [CrossRef]

25. McDaniel, M.; Ingall, E.; Morton, P.; Castorina, E.; Weber, R.; Shelley, R.; Landing, W.; Longo, A.; Feng, Y.; Lai, B. Relationship between atmospheric aerosol mineral surface area and iron solubility. ACS Earth Space Chem. 2019, 3, 2443-2451. [CrossRef]

26. Qi, J.; Zhang, M.; Feng, L.; Li, X. An EXAFS study on the local structure around iron in atmospheric aerosols collected in the Qingdao area. Molecules 2003, 8, 31-39. [CrossRef]

27. Oakes, M.; Weber, R.; Lai, B.; Russel, A.; Ingall, E. Characterization of iron speciation in urban and rural single particles using XANES spectroscopy and micro X-ray fluorescence measurements: investigating the relationship between speciation and fractional iron solubility. Atmos. Chem. Phys. 2012, 12, 745-756. [CrossRef] 
28. Escudero, M.; Querol, X.; Pey, J.; Alastuey, A.; Perez, N.; Ferreira, F.; Alonso, S.; Rodriguez, S.; Cuevas, E. A methodology for the quantification of the net African dust load in air quality monitoring networks. Atmos. Environ. 2007, 41, 5516-5524. [CrossRef]

29. Wilke, M.; Farges, F.; Petit, P.; Brown, G.; Martin, F. Oxidation state and coordination of Fe in minerals: An Fe K-XANES spectroscopic study. Am. Mineral. 2001, 86, 714-730. [CrossRef]

30. Giuli, G.; Pratesi, G.; Cipriani, C.; Paris, E. Iron local structure in tektites and impact glasses by extended $\mathrm{X}$-ray absorption fine structure and high-resolution X-ray absorption near-edge structure spectroscopy. Geochim. Cosmochim. Acta 2002, 66, 4347-4353. [CrossRef]

31. Altermatt, D.; Brown, I. The automatic searching for chemical bonds in inorganic crystal structures. Acta Crystallogr. 1985, B41, 240-244. [CrossRef]

32. Newville, M. Using Bond Valence sums as restrains in XAFS analysis. Phys. Scr. 2005, T115, 159-161. [CrossRef]

33. Suda, A.; Makino, T.; Higashi, T. Extractability of manganese and iron oxides in typical Japanese soils by $0.5 \mathrm{~mol} / \mathrm{L}$ hydroxylamine hydrochloride (pH 1.5). Soil Sci. Plant Nutr. 2012, 58, 684-695. [CrossRef]

34. Suda, A.; Makino, T.; Higashi, T. An improved selective extraction method for Mn oxides and occluded metals with emphasis on applicability to Andisols. Soil Sci. Plant Nutr. 2013, 59, 840-851. [CrossRef]

35. Petroselli, C.; Moroni, B.; Crocchianti, S.; Selvaggi, R.; Vivani, R.; Soggia, F.; Grotti, M.; d'Acapito, F.; Cappelletti, D. Iron Speciation of Natural and Anthropogenic Dust by Spectroscopic and Chemical Methods. Atmosphere 2019, 10, 8. [CrossRef]

36. Federici, E.; Petroselli, C.; Montalbani, E.; Casagrande, C.; Ceci, E.; Moroni, B.; Porta, G.L.; Castellini, S.; Selvaggi, R.; Sebastiani, B.; et al. Airborne bacteria and persistent organic pollutants associated with an intense Saharan dust event in the Central Mediterranean. Sci. Total Environ. 2018, 645, 401-410. [CrossRef] [PubMed]

37. Moroni, B.; Castellini, S.; Crocchianti, S.; Piazzalunga, A.; Fermo, P.; Scardazza, F.; Cappelletti, D. Ground-based measurements of long-range transported aerosol at the rural regional background site of Monte Martano (Central Italy). Atmos. Res. 2015, 155, 26-36. [CrossRef]

38. Draxler, R.; Rolph, G. HYSPLIT. (HYbrid Single-Particle Lagrangian Integrated Trajectory) Model access via NOAA ARL READY; US Department of Commerce: Washington, DC, USA, 2012.

39. Majestic, B.; Schaufer, J.; Shater, M.; Turner, J.; Fine, P.; Singh, M.; Sioutas, C. Development of a wet-chemical method for the speciation of iron in atmospheric aerosols. Environ. Sci. Technol. 2006, 40, 2346-2351. [CrossRef]

40. Pueyo, M.; Rauret, G.; Lück, D.; Yli-Halla, M.; Muntau, H.; Quevauviller, P.; Lopez-Sanchez, J. Certification of the extractable contents of $\mathrm{Cd}, \mathrm{Cr}, \mathrm{Cu}, \mathrm{Ni}, \mathrm{Pb}$ and $\mathrm{Zn}$ in a freshwater sediment following a collaboratively tested and optimised three-step sequential extraction procedure. J. Environ. Monit. 2001, 3, 243-250. [CrossRef]

41. Smichowski, P.; Polla, G.; Gomez, D. Metal fractionation of atmospheric aerosols via sequential chemical extraction: A review. Anal. Bioanal. Chem. 2005, 381, 302-316. [CrossRef]

42. d'Acapito, F.; Trapananti, A.; Puri, A. LISA: The Italian CRG beamline for X-ray Absorption Spectroscopy at ESRF. J. Phys. Conf. Ser. 2016, 712, 012021. [CrossRef]

43. Ravel, B.; Newville, M. ATHENA, ARTEMIS, HEPHAESTUS: Data analysis for X-ray absorption spectroscopy using IFEFFIT. J. Synchrotron Radiat. 2005, 12, 537-541. [CrossRef] [PubMed]

(C) 2020 by the authors. Licensee MDPI, Basel, Switzerland. This article is an open access article distributed under the terms and conditions of the Creative Commons Attribution (CC BY) license (http://creativecommons.org/licenses/by/4.0/). 